\title{
Virtual City as a Place for Educational and Social Activities
}

\author{
doi:10.3991/ijet.v4s2.939 \\ M. Fominykh ${ }^{1}$, E. Prasolova-Førland ${ }^{1}$, M. Morozov ${ }^{2}$ and A. Gerasimov ${ }^{2}$ \\ ${ }^{1}$ Norwegian University of Science and Technology, Trondheim, Norway \\ ${ }^{2}$ Mari State Technical University, Yoshkar-Ola, Russia
}

\begin{abstract}
In recent years, virtual worlds have become increasingly popular in education and social life. Using a 'city' metaphor, we are developing a 3D virtual world enriched with social and educational tools. This virtual world allows performing a number of activities, such as exploring the city, learning and communicating with its citizens, building a social network. In this paper we report the results of case studies we have performed to explore users' activities and behavior in a virtual city context. Our goal was to investigate how such a city can facilitate learning and socializing, also in a cross-cultural context. Based on the empirical results, we derive a list of recommendations for a virtual city as a place for social and educational activities.
\end{abstract}

Index Terms-3D educational virtual worlds, collaborative learning, virtual city.

\section{INTRODUCTION}

During the recent years, 3D virtual worlds have become increasingly popular in educational settings. In [1] we have argued that such virtual worlds have promising potential for supporting learning communities because of their capability to provide a social arena where students and teachers can meet overcoming the barriers of the physical world. According to [2], virtual worlds offer an opportunity for people to interact in a way that conveys a sense of presence lacking in other media. Such environments can provide a social context for learning and a sense of presence, which is important for the students' emotional involvement and implies a level of engagement that might not be present otherwise. The design of educational virtual worlds is often based on the social constructivism approach [3], allowing learners to co-construct their environment and understanding together with their peers.

In this work we focus on a 'virtual city' as a place for social and educational activities. A virtual city can be defined as an environment representing a real or fictional city and supporting a range of different activities for the purposes of education, entertainment and socializing for local communities. Other possible roles of a virtual city include attracting potential tourists, visitors and students and providing them with explicit information about the city, the local educational institutions and so on. Dissemination and sharing of the user-generated content related to the city could also play an important role in this context.

'City' is a powerful metaphor that most people are familiar with. A brief exploration shows that this metaphor is used in quite a broad range of virtual worlds projects [4, 5]. In the virtual city design the quality of environment and the level of detail are often of high importance [6].
Still it is not only an issue of creating a realistic 3D model, but a place that is invested with social meaning. Therefore other questions appear: for what purposes and how virtual cities can be used [6].

The most known virtual cities are made for Geonavigation, such as Google Earth (http://earth.goog le.com), heritage preservation, such as Rome Reborn (http://www.romereborn.virginia.edu) and Forbidden City (http://www.beyondspaceandtime.org), others for gaming and socializing, for example Cybertown (http://www.cy bertown.com) and Citypixel (http://www.citypixel.com). However, virtual worlds that represent the physical world in a very direct and realistic way, known as 'mirror worlds', do not have satisfactory support of learning and socializing [5]. Many of the experiences in these virtual worlds are reported as disconnected with those of their real-world counterparts. At the same time, social virtual worlds, such as Second Life [2], resemble only little parts of real world or even do not have anything in common with the reality.

The work in this paper reports on addressing these issues and outlines a strategy for reconnecting the virtual and the physical in a city context, considering both learning communities and realistic representation. It requires the integration of the $3 \mathrm{D}$ virtual worlds with social software tools as we presented earlier within the concept of Collaborative Virtual Workshop [7]. In general, while virtual worlds focus on collaboration among people that are geographically distributed, the metaphor of "virtual city' brings local issues back into the distributed virtual environment, recognizing the critical role of place and local communities in learning. This not only supports interactions with "others around the world, but also - and, perhaps more importantly, with people nearby" [8]. The challenge therefore is to design, what Thackara calls, new geographies of learning, "configurations of space, place, and network that respect the social and collaborative nature of learning - while still exploiting the dynamic potential of networked collaboration" [9].

In the next section we present 2 empirical studies where we explore the possibilities of using a virtual city for supporting learning communities. Based on the results of these studies, we provide a set of guidelines for designing a virtual city as a place for social and educational activities.

\section{Virtual City as a Place fOR EdUCATIONAL AND SOCIAL ACTIVITIES}

To identify the expectations that learners have of a virtual city and to investigate what functionality and content 
are needed for such a system, we performed 2 studies among the students of the Norwegian University of Science and Technology (NTNU). In the first one the students had a number of educational activities in the Virtual City of Yoshkar-Ola (VCYO).

\section{A. System Description}

This sub-section presents a short description of the system VCYO. In reality Yoshkar-Ola is a little city in the Volga region in Russia, where MMLab (VCYO developer) is located. VCYO is a multiuser virtual environment, providing an accurate recreation of the central part of the real city with buildings (with examples of interiors), streets, yards and other elements (Fig. 1).

The model of the city contains also the main building of NTNU (Fig. 2) as a symbol of collaboration between universities and as a fun element. The system is freeware and available on the web (http://virtyola.ru/index.php?lang= english).

The system's functionality includes realistic customizable avatars with different navigational possibilities, including a big and a mini-map as well as teleportation. Users can communicate to each other by text chatting; voice chatting is under testing.

The system also supports social software functionality. A user can add comments to existing notes or photos, as well as leave own notes and pictures around the world (Fig. 1, Fig. 2). It is also possible to examine descriptions of places and buildings in the city as well as other users' notes and photos. A citizen of the virtual city can also create a social network with other users, filling the profile, adding friends to the friend list, keeping blog and commenting others' blogs. VCYO also contains some educational tools to enable live virtual lectures such as facilities for slide show, video and web.

\section{B. Study Settings}

The goal of the first case study was to investigate how a $3 \mathrm{D}$ virtual city can support collaborative learning and socializing among students.

34 students from NTNU divided into 8 groups participated in the case study, most of them in their 4th year of study; plus a small group of Russian students. The NTNU students included both ethnical Norwegians and exchange students from other cultural backgrounds. The students were given an exercise where during the preparatory phase they were supposed to explore the virtual world of VCYO, aiming at analyzing the different design features used and discussing the usage of virtual worlds for learning and socializing. The students were also asked to make suggestions how they would have designed a virtual campus representing NTNU and a virtual city of Trondheim (where NTNU is situated) in the most appropriate way.

A central task was participation in a virtual lecture. The lecture took place in the open-air auditorium (Fig. 3) in VCYO, where several tools for learning are situated.

Lecture theatre with slide show, web browser and video screens with a pointer, as well as chat were used during the lecture. After the lecture, the students had a discussion on virtual worlds and virtual cities in educational settings.

The students also delivered essays answering a number of questions regarding their experience in the virtual city.

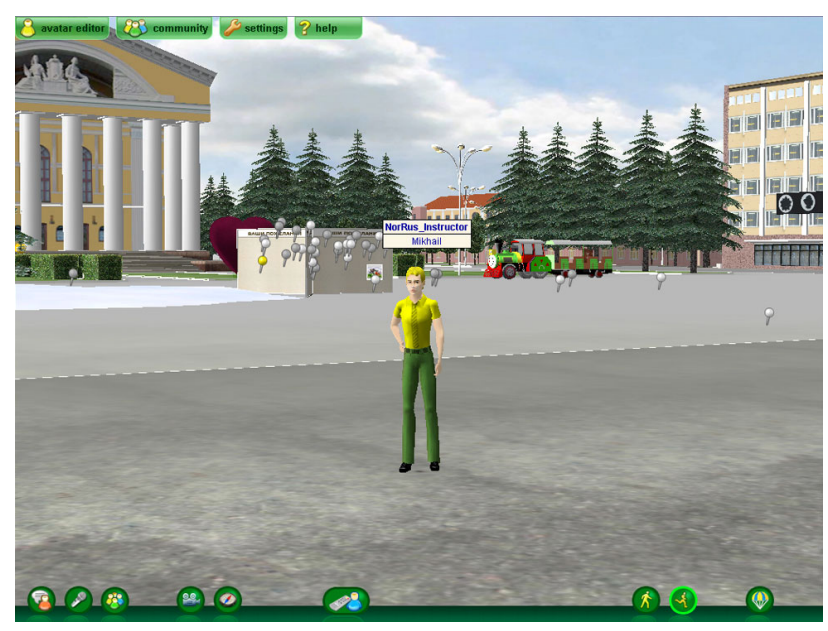

Figure 1. The main square in the Virtual City of Yoshkar-Ola

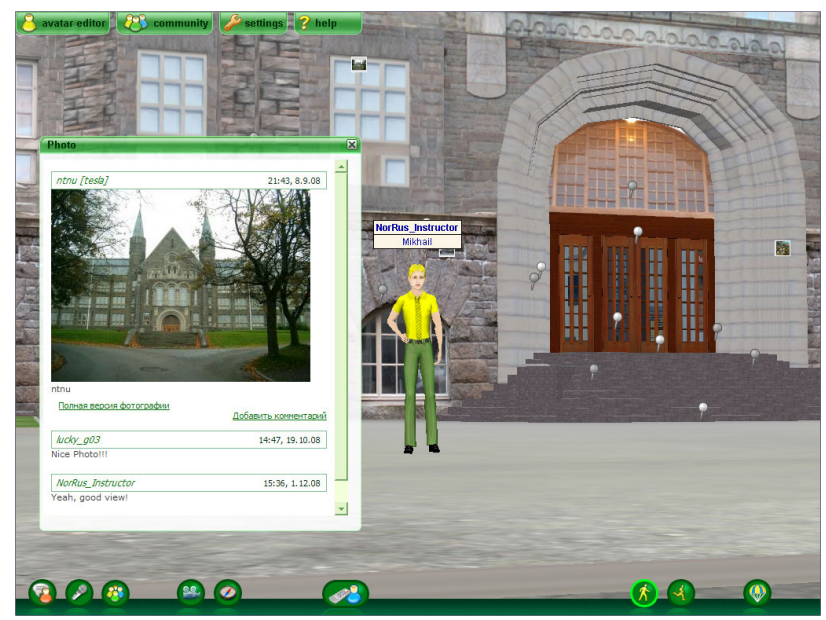

Figure 2. Photo-sharing in the Virtual City of Yoshkar-Ola

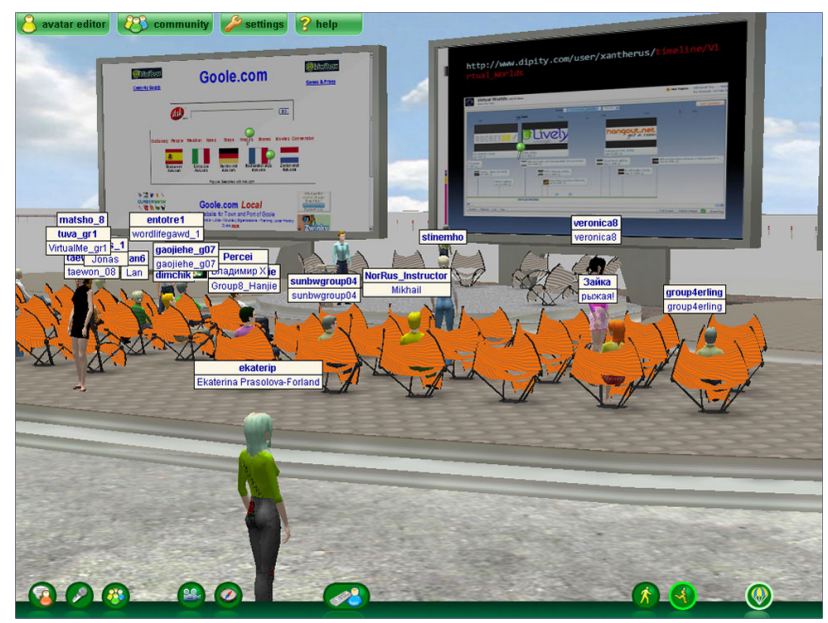

Figure 3. Virtual lecture in the open-air auditorium in the Virtual City of Yoshkar-Ola

All the data in this explorative case study was gathered from the following sources of evidence:

- direct observation of students' activities online;

- archival records (visiting statistics, chat log as well as notes, pictures and comments recording);

- users' feedback (essays and questionnaires) 
We have also performed a study among students taking a different course on an advanced level who are not very familiar with virtual worlds and virtual cities. We distributed a questionnaire among these students with a short definition of a virtual city, asking them to answer the following questions:

- What virtual city would you like to visit/participate in its life?

- What tools and facilities would you need in a virtual city?

- If a virtual city of Trondheim (where NTNU is situated) will be created, would you visit it/participate in its life?

The students were asked to position their answer on a Likert scale. The questionnaire also contained questions on a virtual campus but they are outside the scope of this paper. Out of totally 48 students 26 responded, which constitutes the response rate of $54 \%$.

\section{RESULTS AND DISCUSSION}

\section{A. Results from the case studies}

This sub-section presents the empirical data that was gathered during the case studies. This includes mostly how the students used communication and social software tools, path recording data and some examples, as well as their opinions on the potentials and the usage of a virtual city.

From the 34 students participating in the study, 27 communicated by chat and posted text-notes and pictures. We selected 28 discussions that students took part in from the chat-log (excluding the lecture). Most commonly in these discussions students helped each other to understand the system's functionality details and how to navigate in the virtual city, as well as shared their impressions about the VCYO (Table I). Some of the observed students also met local visitors of VCYO and had some informal conversations. In general, we observed a number of examples of 'social navigation', where the students were guided by peers (for example, how to enter buildings or to get to the lecture place) or invited friends to take a walk on the city's roofs.

Students left 135 notes in the virtual city; some of them were commented by their peers or other virtual citizens. Notes were tagged to particular places so that students from the observed group used them mostly to ask about interesting places, buildings and objects, while local virtual citizens often answered by commenting on those notes (Table II). For example, there were discussions (Table III) around the virtual gallery in VCYO replicating the one available in reality in the city of Yoshkar-Ola (Fig 4). Some of the Norwegian students expressed their interest in the exposition, wishing to learn more about Russian art.

The students from the observed group were interested in the photos of the real city posted in appropriate places in the virtual one; however, they uploaded relatively few pictures of their own. But there was one exception - the main building of NTNU that was created and placed in the outskirts of the virtual city. All of Norwegian students could easily recognize this building and some of them posted photos of it, also leaving a lot of notes discussing the building, the university and other issues (Fig. 2).

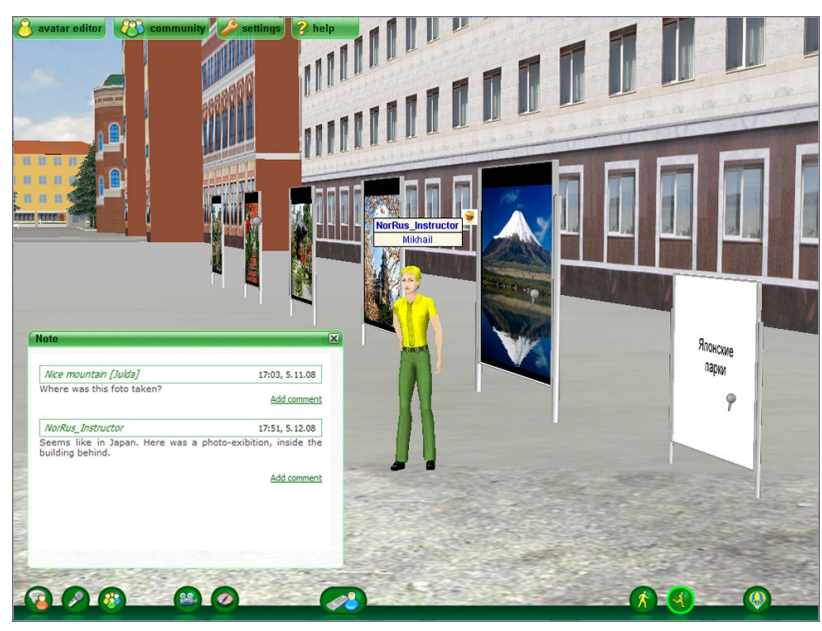

Figure 4. Example of Note with Comments in a Gallery in the Virtual City of Yoshkar-Ola

TABLE I.

Chat Log Fragment

\begin{tabular}{|l|l|}
\hline NorRus_Inst :- & $\begin{array}{l}\text { Veronica, I see you so often here... Do you like } \\
\text { it? }\end{array}$ \\
\hline veronica8 :- & I like it very much \\
\hline NorRus_Inst :- & $\begin{array}{l}\text { Actually this is my hometown :) I haven't been } \\
\text { there 1 year... It is nice to see it in virtuality }\end{array}$ \\
\hline veronica8 :- & It is a beautiful city I think \\
\hline Vego :- & me too Im in Moscow now \\
\hline veronica8 :- & I am often here to get familiar with it \\
\hline NorRus_Inst :- & great \\
\hline veronica8 :- & I have a bad feeling of direction \\
\hline Vego :- & exactly? \\
\hline veronica8 :- & so have to try more and remember road \\
\hline veronica8 :- & and street \\
\hline veronica8 :- & I always get lost in a new city \\
\hline NorRus_Inst :- & Lets go to the roof! \\
\hline veronica8 :- & How to? \\
\hline Vego :- & where is it? \\
\hline Vego :- & ok... show us how \\
\hline NorRus_Inst :- & $\begin{array}{l}\text { We are far away, use global chat, we cant hear } \\
\text { you }\end{array}$ \\
\hline Vego :- & Where are you? \\
\hline NorRus_Inst :- & On the roof of the hotel, you know where \\
\hline NorRus_Inst :- & There is a button to jump on the panel \\
\hline Vego :- & funny bug.))) \\
\hline Vego :- & or is this is a func? \\
\hline NorRus_Inst :- & not a bug ))) \\
\hline veronica8 :- & Great! \\
\hline
\end{tabular}

TABLE II.

EXAMPLE OF NOTE WITH COMMENTS ON A BUILDING

\begin{tabular}{|l|l|l|}
\hline group7_hilde :- & \multicolumn{2}{|l|}{ There is no one inside the building } \\
\hline & hakonje :- & $\begin{array}{l}\text { How do I get inside the build- } \\
\text { ing? }\end{array}$ \\
\cline { 2 - 3 } & lucky_g03 :- & $\begin{array}{l}\text { hay man!! Just right click on the } \\
\text { door and then click the open } \\
\text { option. Thats it }\end{array}$ \\
\hline
\end{tabular}




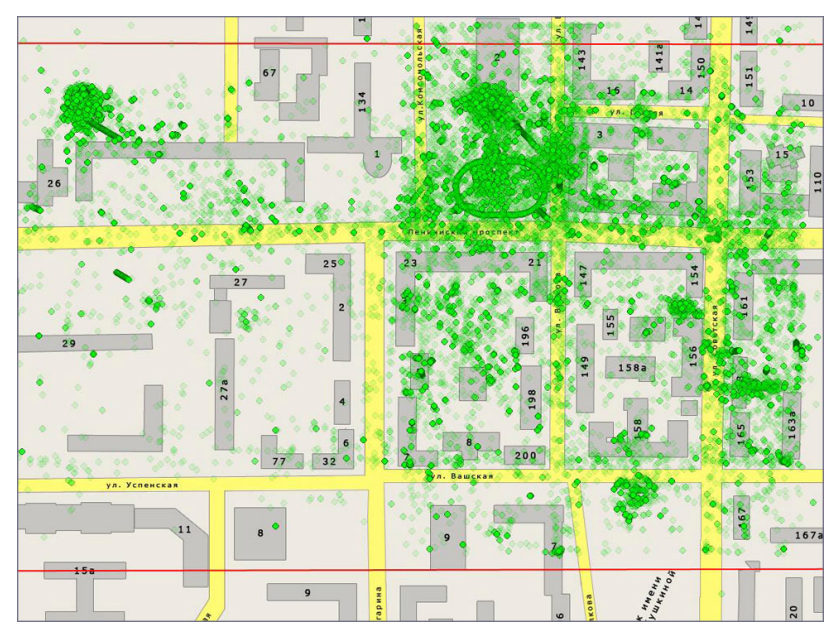

Figure 5. Visiting statistics in the VCYO during the case study (intensity of dots indicate time spent by users)

TABLE III.

EXAMPLE OF NOTE WITH COMMENTS IN A GALLERY

\begin{tabular}{|l|l|l|}
\hline sasaciric:- & \multicolumn{2}{|l|}{ nice photo: not bad, but what is it? } \\
\hline Orchestra :- & $\begin{array}{l}\text { these are photos from art } \\
\text { gallery (a brick building with } \\
\text { a tower). The current exposi- } \\
\text { tion... I don't remember the } \\
\text { name... }\end{array}$ \\
\cline { 2 - 3 } Julda :- & $\begin{array}{l}\text { Which brick building you } \\
\text { mean? and Is this from real } \\
\text { exposition which is now } \\
\text { available in russia? }\end{array}$ \\
\cline { 2 - 3 } & $\begin{array}{l}\text { The building is on the left } \\
\text { side if you look at the pic- } \\
\text { ture:) I think some informa- } \\
\text { tion notes will be tagged to } \\
\text { every building very soon }\end{array}$ \\
\hline
\end{tabular}

Concerning profiles, friend lists and personal blogs functionality, it should be said that it was used to a smaller degree, due to technical problems, relatively small size of the community and a short trial period.

We performed path recordings during the case study (Fig. 5). These data were used to analyze how much time students spent in the virtual city and what places they visited. Students used different 'movement patterns', but most of them explored the city moving towards familiar places (such as the main building of NTNU), discovering other places in the city mostly on the way there. Another discovered trend is the high attention to the fun elements such a moving train on the main square. Most of the students moved in the relative proximity of the default entry point to the system.

The results of the second study are summarized in Figs 6-8.

\section{B. Discussion}

Based on the analysis of the results, we will now discuss how the system's existing functionalities support or limit educational and social experience in the VCYO. We will also discuss what activities and associated tools are suitable in an educational virtual city in general.

The navigation and exploration of the city was mostly concentrated around the default entry and a few other areas of interest such as the main square, the lecture place
Q1. What virtual city would you like to visit/participate in its life?

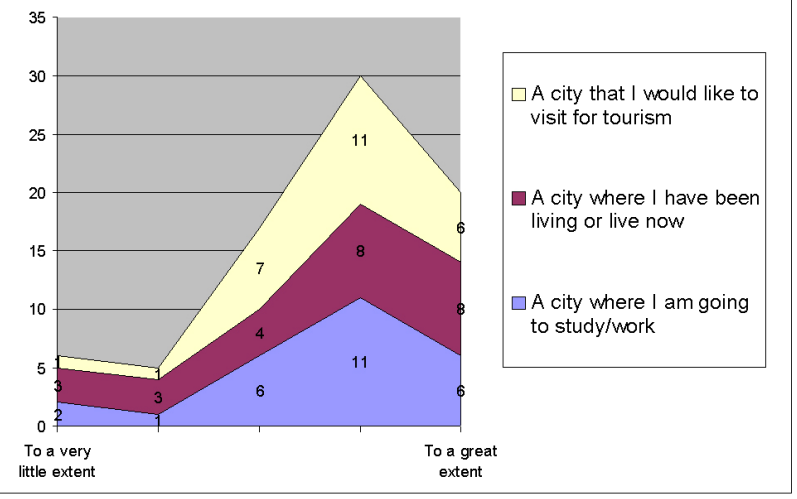

Figure 6. Results: What virtual city would you like to visit/participate in its life?

Q2. What tools and facilities would you need in a virtual city?

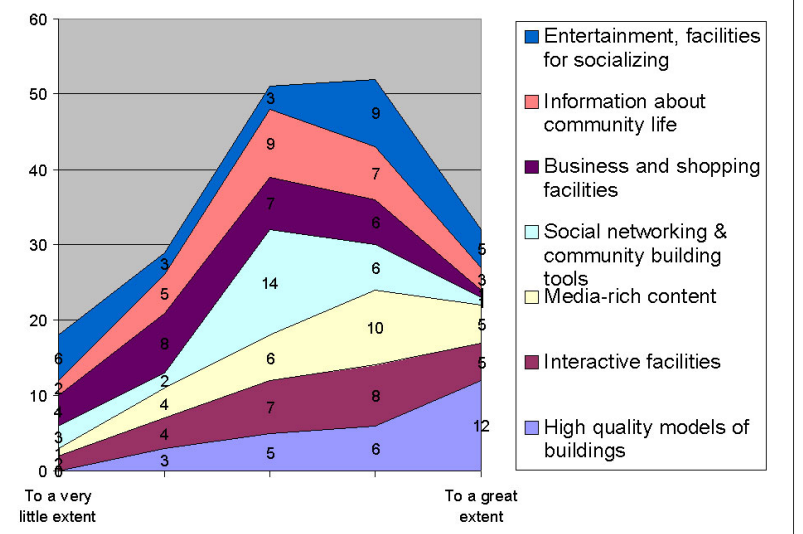

Figure 7. Results: What tools and facilities would you need in a virtual city?

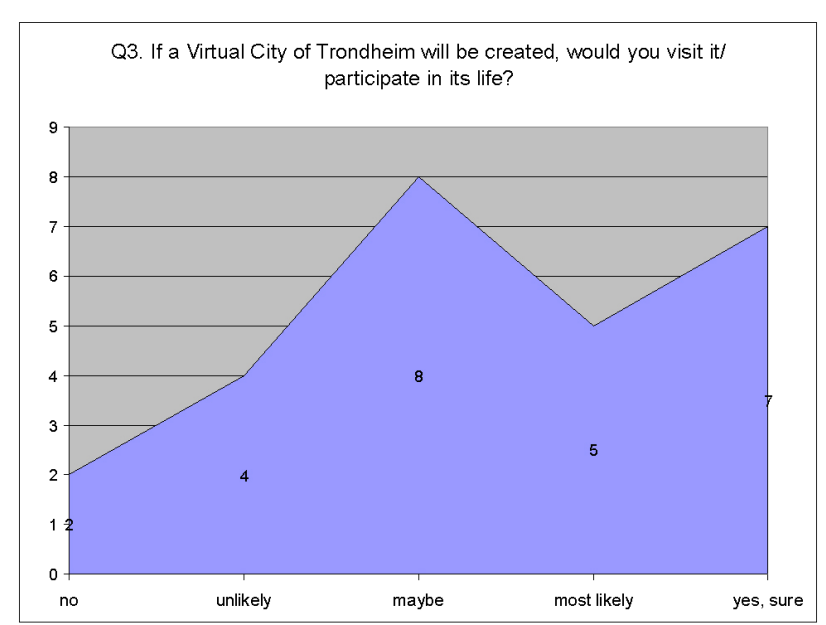

Figure 8. Results: If a virtual city of Trondheim will be created, would you visit it/participate in its life?

and the main building of NTNU as the visiting statistics (Fig. 5) and direct students' feedbacks showed. One of the reasons for that was that the students did not get sufficient information upon log-in about the different places in the city that might be interesting to visit, plus at this stage of development not all constructions had enough informa- 
tional content to motivate in-depth exploration. In addition, existing avatar moving functionality (clicking on the place to move) turned out to be not efficient enough for the target audience used to playing computer games. The majority of students expressed the wish to use arrows or WASD keys. The function allowing jumping turned out to be useful to get an overview and as a 'fun' element. As an improvement a 'flying' mode was proposed, as well as a more transparent, searchable map with information about different locations. Still, the navigation patterns showed that the existing support for social navigation (by chat and leaving notes) was not fully efficient and that additional facilities are needed.

The community network development allowed us to analyze the efficiency and limitations of the different tools in the virtual city context. Considering the small quantity of virtual citizens in this case study, the limited time-span and some technical problems, the resulting community network (in terms of blogs and friend-lists) was moderate but satisfactory. One of the most useful tools was the one allowing to see 'who is on-line' and teleporting to any user from the list. User notes were used quite a lot, allowing students to discuss asynchronously particular places or objects and enriching the environment with user-generated content. Notes with comments often contained quite meaningful discussions and were usually attached to the places related to the discussion topic. For example, there were a lot of notes with questions about buildings and places, highlighting the need for 'tagging the buildings', explaining their purpose. The functionality allowing posting photos was mostly useful in relation to places familiar from reality, showing the importance of the connection between the real and the virtual.

The total amount of notes was less, but comparable to the amount of chat messages - the main communication tool. The findings above suggest that the notes functionality was easy to use and helpful, but most importantly, they highlight the importance of situatedness and context for community development in the virtual city. The students used the virtual city as a discussion board, connecting together the content and virtual places.

Such virtual places within a virtual city can play a number of different roles in an educational context. For example, the streets and squares could serve as natural meeting places, with prominent landmarks such as 'street corners' and famous buildings acting as navigation aids. The same landmarks (such as the main building of NTNU in our example) as well as designated places (libraries, campus, boards at teleportation hubs), where community members can store resources and leave their notes, announcements and comments, function as an information place set in a rich context. In our case, it allowed Norwegian students to learn about a foreign city by posting their questions on the buildings of interest and receiving answers from the locals. Here it is important to introduce mechanisms for structuring and moderating of information, as stressed by the students.

The virtual city can also function as an exhibition (Table III, Fig. 4), attracting public interest for the corresponding event in reality and allowing the community members to post comments and questions. As our experience with the virtual lecture shows, a virtual city can function as a workplace. Still this requires that corresponding facilities are in place. An important aspect here, as noted in almost all students' essays, is the 'disturbance' factor while having a lecture in an open space (a square) with other users wondering around and other visual impressions diverting attention from the lecture itself. It was suggested to keep such 'serious' educational events 'indoors' in settings close to real-life auditoriums, to create a better focus on the educational content. Such open places in the city are better suited serve as 'virtual stages' for concerts, city events and gatherings, promoting a feeling of 'togetherness' and presence among distributed users.

The preliminary study performed among students not very familiar with virtual environments, showed some interesting tendencies. When asked about different types of cities the students would like to visit, the answers were divided approximately evenly between the 3 categories (tourist destinations, place for study/work and home cities), with the slight prevalence for the 2 first categories (Fig. 6). This indicates the need for creation of virtual cities for different purposes. Concerning the tools and facilities, a slight preference was given to the ones enhancing user experience such a multimedia, interactivity and high-quality graphics and models. This corresponds to the feedbacks received from the students who used VCYO, as well as to earlier studies in 3D virtual environments [1]. This shows that these elements should be given a high priority when designing virtual cities for learning. Finally, the majority of the students answered that they would "maybe, most likely or for sure" engage in a virtual city of Trondheim. This supports our idea to create an educational virtual city of Trondheim closely intergraded with the virtual campus of NTNU.

\section{Guidelines for designing an educational virtual city}

Based on the students' direct feedbacks and other empirical data, we can outline the following major guidelines for designing a virtual city as a place for learning (focusing primarily on the city of Trondheim):

The primary purpose of a virtual city and its target audience (e.g. tourists, inhabitants, students) should be kept in mind when creating an initial design. These considerations will affect the weight put on different features such as historical reconstructions and multimedia effects vs. tools for community support. At the same time, in order to create a virtual city that appeals to different user groups and supports a wide range of usage scenarios and situations, it is important to maintain a balance between different design aspects. A way of achieving such a balance might be to ensure sufficient flexibility and expandability of the virtual city so that its design can be easily changed and new features added to address changing needs of the users. Another solution is customized interfaces for different groups of users, allowing different modes of access, exploration and exploitation. For example, a tourist visiting the church of Our Lady in the virtual city of Trondheim would be primarily offered a historical overview while a local visitor would easily find a schedule of sermons and concerts to be held in the church.

The appearance of a virtual city should be as authentic as possible to create a familiar atmosphere, with all the major and most significant buildings and the overall city structure presented in a maximally realistic way. Still, the design of certain places for various educational activities (such as lecture halls and museums) might have a limited reality resemblance to serve the specific goals in a best possible manner. 
City atmosphere plays an important role, according to students' feedbacks. Appropriate music and sounds, moving objects, presence of other users, real or artificial, will contribute to make the virtual world more 'alive' and appealing.

Informational resources should be an essential part of a virtual city as well as a set of tools for content manipulation. It was generally agreed that only models of buildings without corresponding information have a very limited value and meaning, especially for the users not familiar with the city. Therefore, there should be a strong correspondence between the constructions in the virtual city and the associated informational resources and facilities. For example, the city hall should contain information about local government; the doctors' offices should contain information about the medical services. The city should in general contain multimedia resources such as sound, pictures, video and 'enactments' with virtual agents associated with relevant important buildings and landmarks, allowing the users to learn about the city, its history and culture. There should also be a significant support for interactive elements such as adding usergenerated content and educational games.

A wide array of community resources and tools reflecting and supporting the life of the community should be integrated in a virtual city, in a situated and contextualized manner. For example, there should be established virtual places for social activities (imaginary ones or representations of real places) such as squares, parks, art galleries, museums and clubs. Other examples include bulletin boards with announcements, blogs and virtual houses for community members, discussion forums and tools for supporting social networks with extensive possibilities for the users to share, annotate and modify the content. There should be clear connections between the community resources and the related virtual places. A basic support for commercial activities should be provided to ensure better integration of local businesses into the community.

Various navigation facilities should be available for users to access the content in a virtual city in the most efficient way, such as 'city tours' led by agents, and 'transportation routes' marked clearly between different places. A virtual city should also contain 'tourist offices' with information and links to the major points of interest plus searchable maps with filters where one can look for shops, local businesses and historical places. In order to support social navigation, there should be possibilities for sharing information on paths taken and places visited by other users.

Virtual campus in a 'student' city like Trondheim is supposed to act as a natural educational center, providing a broad range of educational resources. At the same time, such resources supporting learning and students' communities and social activities should be integrated throughout the city. Examples include virtual 'concert halls' for student festivals and history lessons in the city streets.

\section{CONCLUSIONS AND FUtURE WORK}

In this paper we discussed the concept of virtual city as a place for educational and social activities. We also pre- sented basic results of 2 empirical case studies, where we explored different aspects of a virtual city as a place for educational and social activities. We analyzed the effectiveness of various tools supporting educational and social activities and suggested directions for their development and improvement. In addition, based on the empirical data, we derived and presented a set of the major guidelines for designing an educational virtual city.

Future research directions will include further work on the VCYO project, designing a virtual city representing Trondheim as well as the development of the theoretical framework for designing educational virtual cities.

\section{REFERENCES}

[1] E. Prasolova-Førland and M. Divitini, "Collaborative virtual environments for supporting learning communities: an experience of use," in ACM SIGGROUP, USA: ACM, 2003, pp. 58-67.

[2] A. J. Kelton, "Second Life: Reaching into the Virtual World for Real-World Learning," ECAR Research Bulletin, 2007.

[3] L. S. Vygotsky, Mind in society: the development of higher psychological processes. Cambridge, MA: Harvard University Press, 1978.

[4] M. Dodge, S. Doyle, A. Smith, and S. Fleetwood, "Towards the Virtual City: VR \& Internet GIS for Urban Planning," in $V R$ and GIS Workshop, London, UK, 1998.

[5] S. de Freitas, "Serious virtual worlds report," Joint Information Systems Committee (JISC) 2008, http://www.jisc.ac.uk/media/ documents/publications/seriousvirtualworldsv1.pdf

[6] W. Dokonal, B. Martens, and R. Plösch, "Creating and Using Virtual Cities," in eCAADe Conference, Copenhagen: Architecture in the Network Society, 2004, pp. 580 - 585.

[7] M. Fominykh, E. Prasolova-Førland, and M. Morozov, "From 3D Virtual Museum to 3D Collaborative Virtual Workshop," in Eighth IEEE ICALT, 2008, pp. 443-445.

[8] H. Rheingold, "Smart Mobs - The Next Social Revolution," Cambridge, MA, Perseus Publishing, 2003.

[9] J. Thackara, "In the Bubble: designing in a complex world," Cambridge, MA, The MIT Press, 2005.

\section{AUTHORS}

M. Fominykh is a PhD-student at the Program for learning with ICT, Norwegian University of Science and Technology, NO-7491, Trondheim, Norway (e-mail: mikhail.fominykh@svt.ntnu.no).

E. Prasolova-Førland is an associate professor at the Program for learning with ICT, Norwegian University of Science and Technology, NO-7491, Trondheim, Norway (e-mail: ekaterip@idi.ntnu.no).

M. Morozov is an associate professor at the Mari State Technical University, head of the Multimedia Systems Laboratory, 424000, Yoshkar-Ola, Russia (e-mail: morozov@marstu.mari.ru).

A. Gerasimov is an assistant professor in the Mari State Technical University, 424000, senior programmer at the Multimedia Systems Laboratory, Yoshkar-Ola, Russia (e-mail: gerasimov.marstu@gmail.com).

This work was supported by the Program for learning with ICT, NTNU and Multimedia Systems Laboratory, MARSTU.

This article was modified from a presentation at the International Conference on Interactive Mobile and Computer Aided Learning (IMCL2009) in Amman, Jordan, April 2009. Submitted, May, 24, 2009. Published as resubmitted by the authors on May, 25, 2009. 